\title{
CARTOGRAFIA DO LITORAL DE FORTALEZA NA DÉCADA DE 1940
}

cartography of the coastaline from Fortaleza in the 1940s

\author{
Fábio de Oliveira Matos* \\ Fábio Perdigão Vasconcelos**
}

\begin{abstract}
Resumo
O artigo trata do processo de implantação do Plano Diretor de José Otacílio Saboya Ribeiro para a cidade de Fortaleza no ano de 1947, destacando sua influência na formação socioespacial do litoral do município. Privilegiando a análise da forma urbana, buscou-se com o estudo das imagens cartográficas, cotejando e confrontando com os registros documentais, à compreensão de como se deu o processo de ocupação da zona costeira fortalezense na década de 1940. Fundado em reflexão caracterizadora da cartografia na construção ideológica do espaço urbano, realizou-se a análise dos registros cartográficos de Saboya Ribeiro, correlacionando-os com outras fontes, notadamente periódicos (Correio do Ceará e O Povo). A partir da reflexão de tais imagens cartográficas é possível perceber a busca na década de 1940 por um novo direcionamento para o litoral fortalezense, passando a servir como ferramentas para solicitação à intervenção pública na estrutura urbana citadina com a proposição na mudança dos usos e ocupações, tornando esse recorte histórico como marco que redirecionou a forma urbis do litoral de Fortaleza.
\end{abstract}

Palavras-chave: Litoral, Urbanização, Cartografia, Fortaleza, Saboya Ribeiro.

\section{Abstract}

This paper discusses the implementation of Fortaleza Master Plan process proposed by José Otacílio Saboya Ribeiro in the year of 1947, highlighting its influence on the socio-spacial coastline of the municipality. The focus of this analysis is on the urban form and we sought to study the topographical plans, comparing and contrasting them with the available documents, so we intend to understand how was the process of occupation of Fortaleza coastline in 1940 decade. The study is based in the topographic plan and seeks the ideological construction of the urban space. In this analysis we used the Saboya Ribeiro's cartographic images file, correlating them with other sources, especially newspapers (Correio do Ceará and O Povo) From the discussion of those topographic plans it is possible to notice the searching of a new direction to the coastline of Fortaleza in the 1940 decade. The coastline was employed as an argument for public urban structure interventions with the changing of the use and occupation of the land, making this historic period as a milestone that redirected the forma urbis of Fortaleza coastline.

Key words: Coastline, Urbanization, Cartography, Fortaleza, Saboya Ribeiro.

\section{Résumé}

L'article traite du processus de mise en œuvre du Plan Directeur José Otacilio Saboya Ribeiro pour la ville de Fortaleza en 1947, soulignant son influence sur la formation socioespacial du littoral de la municipalité. Centré sur l'analyse de la forme urbaine, nous avons cherché à étudier des images cartographiques, en faisant des comparaison et contraste avec les dossiers documentaires, de comprendre comment a été le processus d'occupation de la zone côtière de Fortaleza dans les années 1940. A partir d'une réflexion sur la cartographie dans la construction idéologique de l'espace urbain, nous avons effectué l'analyse des documents cartographiques de Saboya Ribeiro, en les corrélant avec d'autres sources, notamment les quotidiens (Correio do Ceará e O Povo). À partir de l'analyse de ces images cartographiques c'est possible voir une nouvelle direction pour la côte de Fortaleza, transmettre la demande de servir d'outils d'intervention publique dans la structure urbaine de la ville avec la proposition de changement d'occupation et d'usage du sol, faisant de cette période historique un indicateur qui a redirigé la forma urbis la côte de Fortaleza.

Mots-clés: Zone cotiére, Urbanisation, Cartographie, Fortaleza, Saboya Ribeiro.

(*) Doutorando no Programa de Pós-graduação em Geografia da Universidade Federal do Ceará - Grupo de Pesquisa Gestão Integrada da Zona Costeira da Universifdade Estadual do Ceará, Av. Paranjana, 1700 - CEP: 60740-000 - Fortaleza (CE) - Brasil. Tel: (+55 85) 31019792 - fabiomoria@yahoo.com.br

(**) Prof. Dr. do Programa de Pós-Graduação em Geografia da Universidade Estadual do Ceará - Grupo de Pesquisa Gestão Integrada da Zona Costeira da Universidade Estadual do Ceará, Av. Paranjana, 1700 - CEP: 60740-000 - Fortaleza (CE) - Brasil. Tel: (+55 85) 31019792 - ffabioperdigao@gmail.com 


\section{INTRODUÇÃO}

Sob o ponto de vista geohistórico, Fortaleza apresenta um extenso trabalho de produções cartográficas que retratam sua forma urbis, possibilitando a reflexão sobre o conjunto urbano da capital cearense. Quer sejam reproduções fidedignas ou esboços de projetos idealizados para a cidade, tais registros permitem contribuir para a construção da história urbana que perpassa o município ao longo dos seus 285 anos.

Para este trabalho o elemento cartográfico será considerado a partir das considerações de Lévy (2008, p. 153-154), ao considerar o mapa como um tipo de linguagem duplamente particular, inserindo-o num meio termo entre o simbólico puro (como a pintura abstrata ou os enunciados matemáticos) e o figurativo (fotografia, cinema). Tal entremeio o configura como uma oposição às linguagens visuais sequenciais, uma vez que possibilita a visualização da informação a ser captada num conjunto imagético.

Por meio dos registros cartográficos é possível empreender não apenas levantamentos de localização ou de planejamento urbano, mas possibilita também o enveredamento nos registros temporais dos discursos subjacentes aos mapas e, consequentemente, da própria localidade que o dá forma.

Partindo dessa perspectiva este trabalho encontra-se estruturado em duas partes. Num primeiro momento, apresentaremos o contexto geohistórico no qual o litoral de Fortaleza encontra-se inserido ante o processo de constituição do plano urbanístico de Saboya Ribeiro na década de 1940, dando ênfase para a questão portuária perpetrada no munícipio. A segunda parte trata desse plano urbano, destacando as projeções de Saboya Ribeiro para a zona costeira fortalezense.

\section{REPRESENTAÇÃO E CARTOGRAFIA}

Ao utilizar a Cartografia como fonte de pesquisa é fundamental destacar que se trata de um tipo de representação cuja produção não está alheia às percepções, valores e concepções de mundo daqueles que a produziram, bem como das sociedades em que viveram. Tucci (1984) assevera que os mapas não podem ser tomados como uma materialização de conhecimentos geográficos, nem reduzidos a uma técnica, ou a um conjunto de metodologias adotadas na superação de problemas de representação estritamente geométricos, "porque assumem significações e atendem a propósitos os mais variados em razão do contexto em que foram produzidos" (TUCCI, 1984, p. 54). Tal proposição é reforçada por Lacoste (1973):

O mapa, talvez a referência central da geografia, é, e tem sido, fundamentalmente um instrumento de poder. Um mapa é uma abstração da realidade concreta que foi desenhado e motivado por preocupações práticas (políticas e militares); é um modo de representar o espaço que facilita sua dominação e seu controle (p. 1)

No entanto, é preciso ter cuidado ao tratar da cartografia histórica de uma determinada localidade, dado a possibilidade subjetiva inerente aos mesmos. Assim como uma fotografia nem sempre é o retrato real daquilo que se encontra representado em seus registros, ou como o cinema possibilita a formação de meias verdades, como o destino dado por Tarantino à Adolf Hitler em Inglourious Basterds (2009), um mapa, com suas características permeando tanto a ciência quanto a arte, possibilita a formação de inúmeras armadilhas. Apesar de buscar apresentar recortes de uma determinada porção do espaço, a realidade proposta nos mapas não se encontra alheia à ótica de seu compositor, bem como os limites técnicos ou ideológicos da época.

Assim, concordamos com Knauss (1997, p. 97) quando assinala que é preciso definir a cartografia - quer seja enquanto arte ou ciência - como uma forma de expressão e o mapa como o suporte material da imagem do espaço. Assim a Cartografia Histórica pode ser delineada como representação do espaço, conceitualmente demarcada e condicionada historicamente. Pertence, assim, ao campo da ciência social que versa acerca das representações do espaço. 
Longe de ser uma reprodução fidedigna do real, a produção cartográfica pode também resultar de projetos nem sempre realizados. No entanto, além de ser "[...] um exercício metodológico que aproxima Geografia e História" (SOUSA, 2002, p. 174) sua importância adquire relevância ao possibilitar o direcionamento da pesquisa para outro patamar, a ocupação do espaço pode ser analisada a partir da interpretação da representação dos lugares cartografados.

Tais observações são essenciais ao analisar a história cartográfica de Fortaleza. Tendo os mapas como papel de destaque na geo-história do município estes, ao buscar delinear a cidade em determinados momentos de sua formação, apresentam em seus registros a carga ideológica daqueles que às produziram. Essa afirmação é possível de ser notada em mapas clássicos da história do município (Figura 1), como na Primeira Planta da Vila de Fortaleza, de Manuel Francês, no qual por meio de uma supervalorização da infraestrutura busca sob o aporte do registro cartográfico a elevação de Fortaleza para vila.
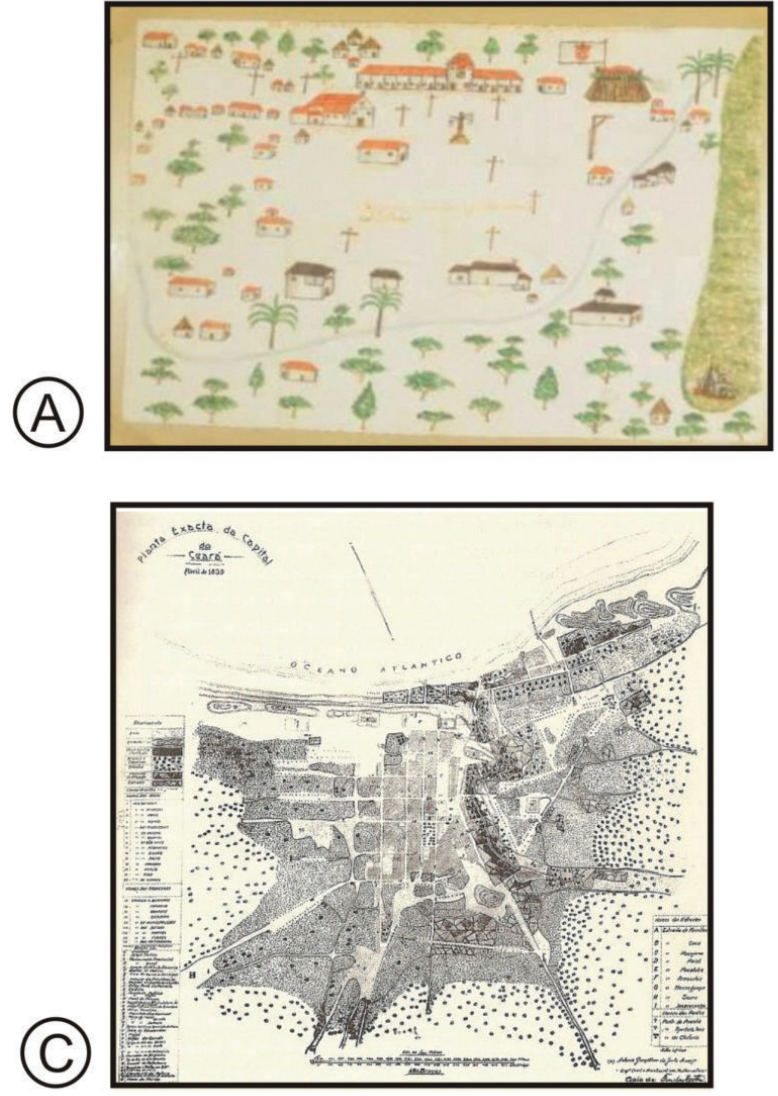
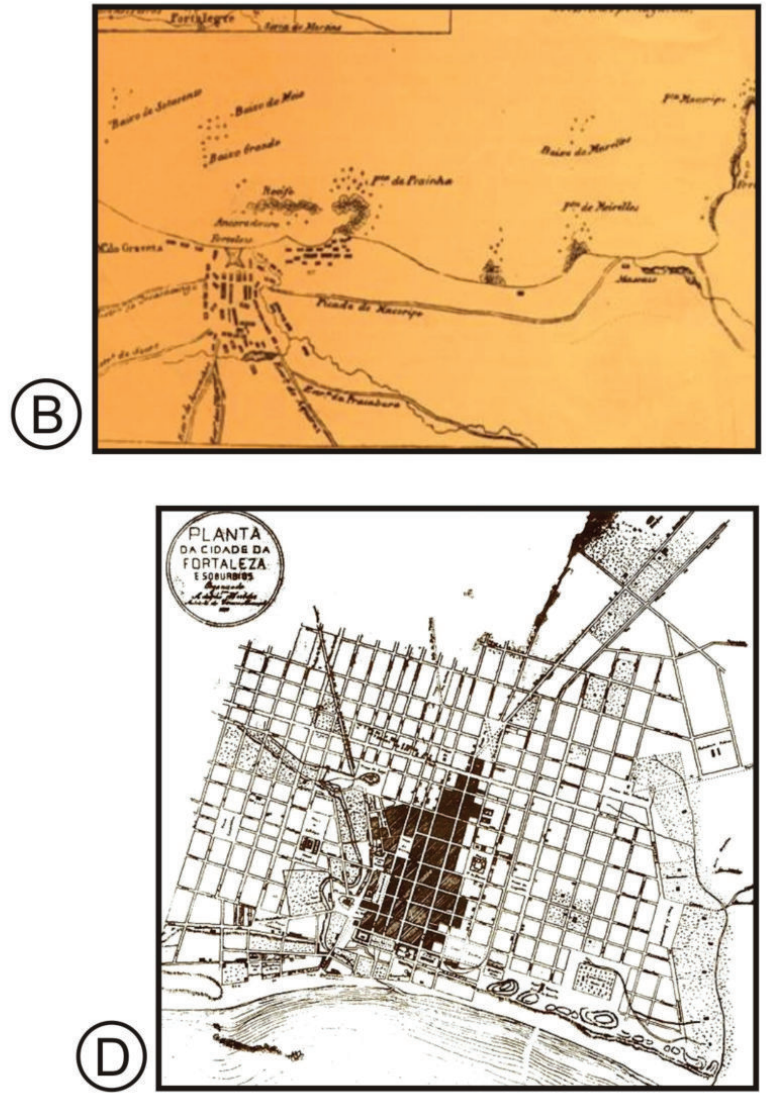

Figura 1 - A) Primeira Planta da Vila de Fortaleza, de Manuel Francês (1726); B) Planta da Vila de Fortaleza, de Silva Paulet (1818); C) Planta Exacta de Fortaleza, de Adolfo Herbster (1859); D) Planta Topográfica de Fortaleza e Subúrbios, de Adolfo Herbster (1875).

Fonte: Arquivo Nirez

Silva Paulet, um dos maiores representantes da cartografia fortalezense também buscou por meio de suas produções o estabelecimento do perfil urbano da capital cearense, além de buscar soluções para a expansão citadina. Interesse compartilhado com Adolfo Herbster, que por meio de projeções cartográficas propondo a formação de arruamentos em xadrez retrata a preocupação sobre formação urbanística do município.

Ao longo da história cartográfica local é possível perceber também o destaque dado na reprodução do espaço litorâneo, configurando um complexo exercício para os urbanistas da época a inserção dessa área na constituição urbis fortalezense. Assim como ocorrido em diversas cidades litorâneas brasileiras, a expansão urbana da capital cearense ignorou ao longo do século XIX e parte do século XX a paisagem costeira em prol da cultura interiorana. 
A preocupação relacionada com os usos do litoral - notadamente a ocupação portuária apresenta-se ao longo da constituição cartográfica fortalezense. Silva Paulet, cartógrafo oficial da primeira metade do século XIX, com sua formação ligada à Marinha Real, apresentou em seus registros características que se aproximava às cartas náuticas, dado o interesse em compreender o calado da zona costeira local.

No entanto, à exceção de Paulet, o litoral do município de Fortaleza permanece sem grandes destaques nas produções cartográficas, reproduzindo o desinteresse da sociedade pelos espaços costeiros, destinados às ocupações mais insalubres, como o Gasômetro, o Paiol da Pólvora e o depósito de lixo. O espaço entre o mar e essas edificações, passou a ser ocupado pelo comércio de exportação, próximo ao desembarcadouro e o Arraial Moura Brasil, formado pela população sertaneja foragida da seca. Essa população indigente "vai se alojando em barracos em terrenos próximos à ferrovia, às indústrias, à zona de praia e às margens dos rios, áreas desprezadas pelos grupos sociais de maior poder aquisitivo" (COSTA, 2005, p. 71).

A zona portuária, incipiente frente ao crescimento de Fortaleza, passa a ganhar papel de destaque entre os urbanistas do final do século XIX. Adolfo Herbster, através de seus estudos e compilações cartográficas já propunha nesse período uma preocupação com a infraestrutura portuária:

Transmitto (sic) a V. Exa ${ }^{\text {. }}$, afim de que o informe com o que se offerecer (sic) o incluso requerimento, em que o Engenheiro Civil Adolpho Herbster residente nessa Província solicita do Governo privilegio para construir uma doca no porto da Capital da mesma Província para facilitar o embarque e desembarque dos gêneros e mercadorias (BRASIL, 1862, p. 7)

O porto, por seu papel de espaço de troca de mercadorias expelia a ocupação pelas classes abastadas, favorecendo a ocupação dos agentes que tinham ligações diretas com o ambiente portuário: as prostitutas, os bares, e os estabelecimentos de jogos de azar para os catraieiros. Somente nas décadas iniciais do século XX que Fortaleza passa a desfrutar de novas perspectivas associadas ao seu ambiente litorâneo, trazendo consigo a necessidade de repensar o espaço citadino.

É nesse contexto que se insere o papel desempenhado pela imagem cartográfica na década de 1940, e sua relação com o ordenamento citadino na zona costeira de Fortaleza. Partindo da preocupação por uma nova configuração urbana para a localidade, Saboya Ribeiro elabora ao longo desse momento histórico uma série de representações e proposições cartográficas sob a forma de plano diretor para o município.

\section{A ZONA PORTUÁRIA NO CONTEXTO URBANO DE FORTALEZA}

Fortaleza, assim como boa parte das cidades litorâneas do país, teve sua gênese urbana direcionada de costas para o mar. Somente no início do século XX, com a inserção de práticas marítimas modernas de lazer originadas a partir da eclosão da efervescência do período da Belle Epoque trazido da Europa, que a capital cearense passa a inserir a paisagem litorânea no seu cotidiano.

Vale destacar, como frisa Dantas (1998), que a descoberta da praia pela elite nos anos iniciais do século XX não corresponde a uma reorientação instantânea do crescimento da cidade para a zona de praia, tratando-se de uma política pontual de ocupação da praia do Peixe, em resposta à demanda da população pelos banhos de mar. No entanto, aos poucos o contexto litorâneo passa a inserir-se no dia-a-dia da população, eclodindo a necessidade de um novo planejamento urbano para a capital que inserisse a zona costeira.

A década de 1930 aporta em Fortaleza marcada pelas políticas de intervenções empreendidas pelo então prefeito Raimundo Girão, que mesmo com o fracasso da efetivação de projetos urbanos anteriores, como o Plano de Nestor de Figueiredol (Figura 1), não havia desistido de dotar a cidade de estratégias que visassem o ordenamento urbano nos limites do município. 


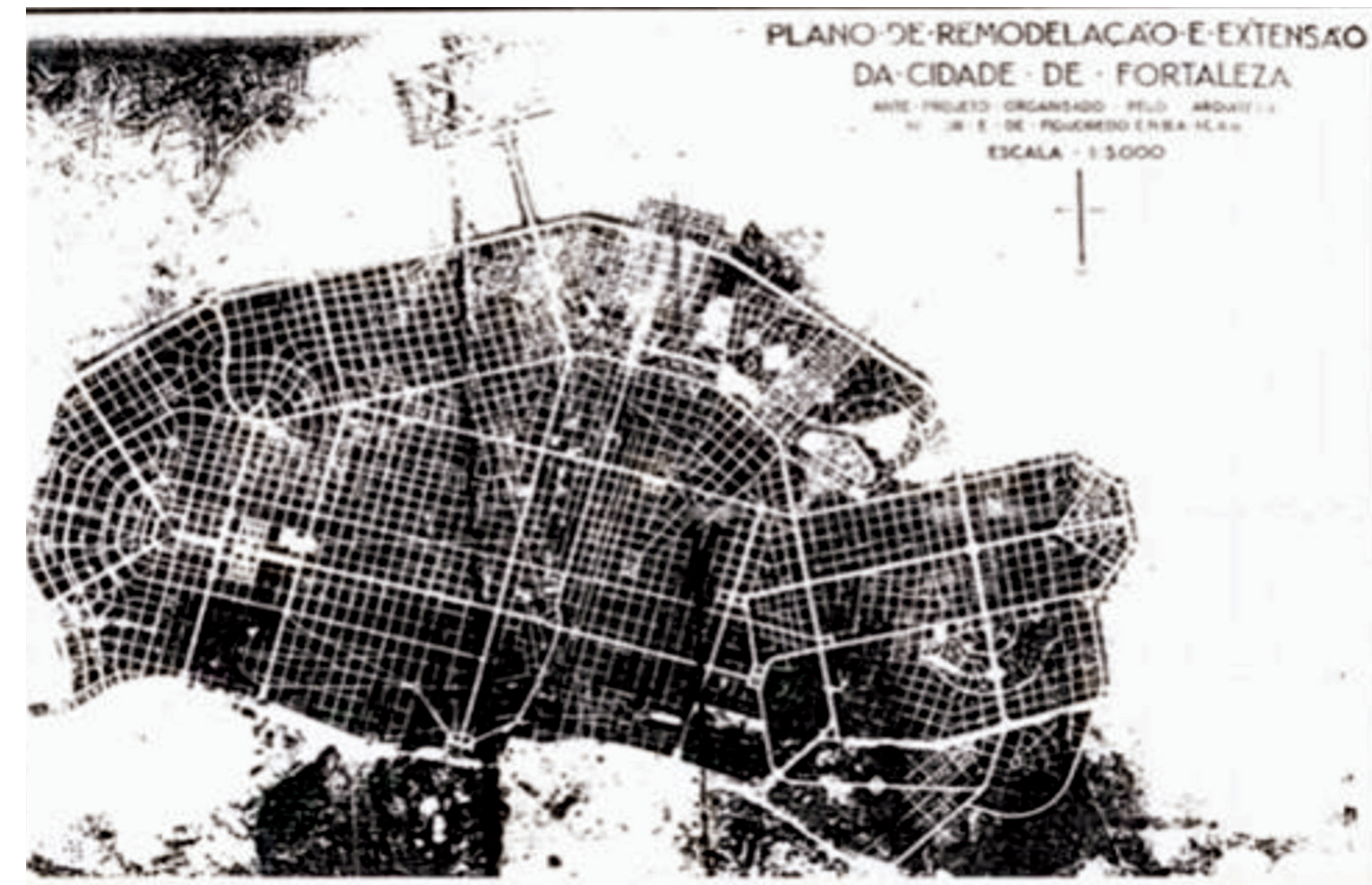

Figura 2 - "Plano de Remodelação Extensão da Cidade de Fortaleza". Planta do sistema viário do anteprojeto do Plano Nestor de Figueiredo para Fortaleza (1933). Fonte: Figueiredo, 1933.

Nos seus estudos sobre os planos urbanísticos de Fortaleza, José Albio Moreira de Sales escreve sobre o papel do anteprojeto de Nestor de Figueiredo para a projeção do futuro da cidade:

O anteprojeto de Plano de Nestor de Figueiredo e o Código de 32, refletiam os anseios de setores da sociedade fortalezense, que na década de 30 já estavam em contato com os novos ideais de Cidade e Modernidade, da emergente sociedade urbana brasileira. Essa parcela da sociedade através de seus representantes na administração municipal ávida pela "modernização" da cultura local e consequentemente, da melhoria do padrão de vida urbana, esperava que um "Plano de Remodelação e Extensão" para a cidade, a exemplo do que já havia acontecido em outras capitais, como São Paulo e Rio de Janeiro, pudesse acelerar o processo (SALES, 1996, p. 96)

Atendo-se à imagem do anteprojeto de Nestor de Figueiredo, intitulado como Plano de Remodelação e Extensão da Cidade de Fortaleza é possível verificar a proposta do aumento de vias de circulação com direção à zona costeira, sobretudo à praia de Iracema, além de vias em formato radial partindo da zona do porto.

A proposição de ruas em formato radiocêntrico partia da crítica do urbanista ao formato xadrez, que segundo ele, era o responsável pela crise urbana da cidade:

[...] verificamos que o sistema de urbanização que orientou a cidade desde o ano de 1800 até os nossos dias, resolveu, em parte, sem atropelos, as suas necessidades. [...] Mas foi esse principio de cruzamento retangular de ruas e avenidas que congestionou os grandes centros de Buenos Aires e Filadélfia, por que, tal qual a cidade de Fortaleza, essas duas importantes cidades do nosso continente têm o traçado das ruas em formato de xadrez. (FIGUEIREDO, 1933, p. 4)

É na gestão de Raimundo Girão (1932-1934) que ocorre em Fortaleza um direcionamento à temática da ordenação urbana, resultando no prolongamento de importantes ruas da capital cearense, como a Liberato Barroso, Barão do Rio Branco e Major Facundo, além de preocupações estéticas a fim de trazer para a cidade a idéia do International Style de Le Corbusier (BAKER, 2006), no qual trouxe com seu discurso arquitetônico funcionalista a mudança de alguns equipamentos urbanos, 
como a demolição do icônico coreto central da praça do Ferreira para dar lugar a moderna arquitetura da Coluna da Hora (BORGES, 2006, p. 63).

Seguindo o projeto de reforma urbana ocorrem importantes intercalações de ruas com o objetivo de ligar alguns setores do município à zona portuária, que é inserida de forma efetiva na dinâmica urbana a partir da conexão das avenidas Visconde do Rio Branco, Sena Madureira com a rua Conde D'Eu, que além de estabelecer uma maior comunicação com a zona do porto, marca também o processo de ligação do centro da cidade com os bairros e distritos situados ao sul de Fortaleza, notadamente o bairro Joaquim Távora e o distrito de Messejana (SOUZA, 1995, p. 58).

Na nova lógica urbana percebemos que apesar da notável ineficiência do porto de Fortaleza, localizado na Praia de Iracema, todos os projetos pensados mantinham a zona portuária na mesma área. No entanto, ao buscarem "um porto definitivo e único, dando abrigo e atracação a embarcações de qualquer calado até 10 metros, acessível em qualquer maré" (GIRÃO, 1997, p. 216) a Praia de Iracema, que concentrava ao mesmo tempo a zona do porto e da balneabilidade da elite, mostrava-se cada vez menos eficiente no papel de receptor portuário.

Visava-se uma zona portuária que crescesse á proporção da cidade. No entanto, se a população de Fortaleza havia aumentado $130 \%$ nas três primeiras décadas do século XX, a expansão das atividades do porto não poderia crescer à mesma medida, devido a dois fatores: a falta de características morfoestruturais básicas de uma zona de porto, notadamente um calado amplo e estrutura em formato de pontal, bem como o complexo convívio entre as classes abastadas que mantinham segundas residências nas áreas próximas da zona portuária.

Com a chegada da energia elétrica na Praia de Iracema, amplia-se o número de bangalôs na orla da cidade, devido a maior comodidade proveniente da eletricidade. Além dos bangalôs surgia também a moda dos clubes sociais localizados à beira-mar. É destaque dentre esses novos equipamentos de lazer o Náutico Atlético Cearense, criado em 1929, que se resumia a "uma pequena guarita de madeira destinada à troca de roupa dos banhistas fundadores" (FREITAS, 2005, p. 93), e o Ideal Clube, que "congregava o que havia de mais tradicional na classe abastada da cidade, que também instalará sua sede praiana em finais de 1930" (FREITAS, 2005, p. 93).

A rejeição ao porto próximo da cidade só não se acentuava devido ao uso que a sociedade tinha com algumas navegações que ali atracavam para a realização de viagens de lazer e trabalho. No final da década de 1920 os paquetes da Agência Lloyd Brasileiro mantinham viagens para Belém, Barbados e Nova York (Paquete Uberaba), Belém (Paquete Goyas) e para Natal, Recife, Maceió, Bahia, Victoria e Rio de Janeiro (Paquete Bahia) (VIAGENS..., 1929).

No entanto a leva de flagelados cearenses que desembarcavam na Ponte Metálica retornando do fracassado sonho da borracha do norte do país, provocava novas discussões acerca do fluxo da zona portuária e da necessidade de distanciamento deste equipamento da dinâmica urbana da cidade.

Surge na cidade algumas propostas de solucionar a explosão de flagelados advindos das embarcações do Norte. O jornal Correio do Ceará relata em suas páginas algumas formas de buscar o controle da crise da emigração da borracha:

AVISO

O Lloyd não fornece mais passagens aos cearenses que queiram regressar a este Estado - Dolorosa situação.

Belém, 2-O agente do Lloyd aqui recebeu ordem superior para suspender o fornecimento de passagens aos flagelados que desejam regressar para o Ceará.

Existem actualmente (sic), nos armazéns da Alfândega, mais de trezentos homens que aguardavam um vapor, a fim de regressar para esse Estado.

O inspetor da Alfândega, presidente da commissão proteccionistas dos flagellados (sic), conferenciou com o Governador Sousa Castro, a respeito da situação em que ficaram os pobres emigrantes cearenses. (AVISO, 1921, p. 7). 
O porto vivia, portanto, seus últimos momentos à vizinhança dos bangalôs da Praia de Iracema. Com os abastados convivendo cada vez mais próximo da zona portuária, os navios estavam próximos a desembarcar em outros ares, o que promoveria uma intensa modificação em toda orla do município. Com base nos estudos realizados em Fortaleza, o Dr. Hor Meyll apresentou, em 21 de Janeiro de 1930, o seu projeto de construção do Porto do Ceará em Mucuripe (GIRÃO, 1997, p. 220), ainda distrito longínquo da capital, que ainda não havia sido pontuado nos projetos urbanos até então e pouco tinha destaque nos bancos de imagens da cidade, com rara exceção a paisagem entorno do farol.

Porém ainda na década de 1930 foram inúmeras as obras na tentativa de aumentar o calado do antigo porto para os navios poderem atracar até a ponte de desembarque. Uma delas foi a inauguração em 24 de janeiro de 1928 da nova Ponte Metálica, agora denominada Viaduto Moreira da Rocha, em homenagem ao Governador do Estado que a inaugurou. Esta obra, a cargo de Francisco Sabóia de Albuquerque constou principalmente na substituição da estrutura metálica, devido sua corrosão pela maresia, sendo reconstruída em concreto, além do aumento do alcance da ponte (FINALMENTE..., 1928).

Tal situação se deu devido ao fato das problemáticas orçamentárias em transferir o porto para a região do Mucuripe, justificado pela distância daquela praia do núcleo urbano do município (GIRÃO, 1997). A Estrada do Mucuripe observada desde a planta de Silva Paulet de 1818 ainda era a única via de ligação desta praia ao centro urbano de Fortaleza, dificultando o acesso dos banhistas e a promulgação do novo porto.

No entanto, após o fracasso estrutural do Viaduto Moreira da Rocha é intensificado o discurso de especialista sobre a necessidade de transferência do porto. O engenheiro Hor Meyll já alertava num relatório em 1930 que "[...] ou temos o porto na enseada do Mucuripe, ou nunca teremos um porto em Fortaleza" (GIRÃO, 1997, 216). Dessa forma, após vários embates entre técnicos portuários brasileiros e estrangeiros é aprovado o Decreto Federal $n^{0}$ 544, de 07 de Julho de 1938, que afirmava:

Art. 1 - transferida a localização do porto de Fortaleza para a enseada do Mucuripe, a que se refere à concessão outorgada ao Estado do Ceará pelo Decreto n 23.607, de 20 de Dezembro de 1933 para a construção, aparelhamento e exploração do referido porto.

Art. $2^{\circ}$ - fica aprovado, em substituição ao de que trata o Decreto ${ }^{\circ} 1680$ de 25 de março de 1937 , o novo projeto e respectivo orçamento, na importância de 38.896.260\$000 (trinta e oito mil contos, oitocentos e noventa e seis mil duzentos e sessenta reis) para a construção do Porto do Mucuripe, no mesmo Estado (GIRÃO, 1997, p. 217).

Esse decreto vem em substituição ao anterior, de 7 de Julho de 1937, que mantinha a construção do novo porto nas imediações do Viaduto Moreira da Rocha. Dessa forma, deu-se em 23 de Julho de 1938, pela Companhia Nacional de Construções Civis e Hidráulicas (Cilvihidro), sediada no Rio de Janeiro e especializada em construção de portos, a construção do porto do Mucuripe (RODRIGUES; SOUSA FILHO, 2007, p. 48).

\section{O PLANO DIRETOR DE JOSÉ OTACÍLIO SABOYA RIBEIRO}

Frente a essa nova situação presenciada pela cidade, e associado ao fracasso do projeto de Nestor de Figueiredo é solicitado ao urbanista Saboya Ribeiro, pelo então Interventor do Ceará José Machado Lopes em 1945, a elaboração de um novo projeto urbano para Fortaleza.

A fim de evitar a não aceitação de seu projeto como o ocorrido com o projeto de Figueiredo, Saboya Ribeiro realizou por quase dois anos um detalhado banco de informações sobre a cidade, realizando uma ampla tabulação preliminar de dados, além de pesquisa de campo para o levantamento das principais necessidades urbanas do município. Dessa forma passa-se quase dois anos para a entrega de um novo plano urbano para a cidade, sendo apresentada a síntese do plano diretor ao 
prefeito da capital, Clóvis de Alencar Matos em 1947. Em seu memorial, Saboya Ribeiro apresentou os objetivos gerais desse plano:

1) o traçado de um sistema de avenidas, em que procuramos assimilar o plano atual de um sistema radial-perimetral, favorecido, em parte, pela formação da própria cidade;

2) o traçado de vias necessárias ao saneamento urbano, ao longo dos córregos que atravessam a cidade;

3) a localização de novos espaços - praças, jardins, parques, reservas arborizadas, etc. - nos diversos bairros, antes que as construções nos mesmos se adensem;

4) o aproveitamento do vale do Pajeú, nas adjacências do centro comercial, de modo a recuperar as áreas de valôr (sic) muito reduzido, transformando-as em áreas úteis e necessárias ao embelezamento e extensão do centro urbano, destinando essas áreas à formação de um centro cívico;

5) criação de um bairro popular na zona do arraial Moura Brasil, aproveitando, destarte, uma zona de valor apreciável, para localização de habitações destinadas às classes populares, cuja atividade se processa no centro urbano e em suas adjacências;

6) a articulação do sistema de transporte - ferrovias, portos marítimos e aeroportos - com o plano das avenidas, de modo a permitir a circulação da riqueza do Estado através da Cidade, sem perturbar o desenvolvimento desta, nem ser pelo mesmo perturbado;

7) a fixação dos limites da cidade, que deverá conter uma população não inferior a 400.000 habitantes (RIBEIRO, 1955, p. 232)

Ao observar o Plano de Remodelação e Extensão de Saboya Ribeiro (Figura 3) notamos que Fortaleza caracterizava-se por uma parte de ocupação mais densa nos bairros do Centro, Joaquim Távora, Praia de Iracema, Benfica, Farias Brito, e começo da Aldeota, até o Colégio Militar de Fortaleza. Ao leste percebe-se essa ocupação de forma mais rarefeita até a atual avenida Barão de Studart, estando apenas delimitados os loteamentos da Aldeota, ao norte da avenida Santos Dumont até a rua Frei Mansueto.

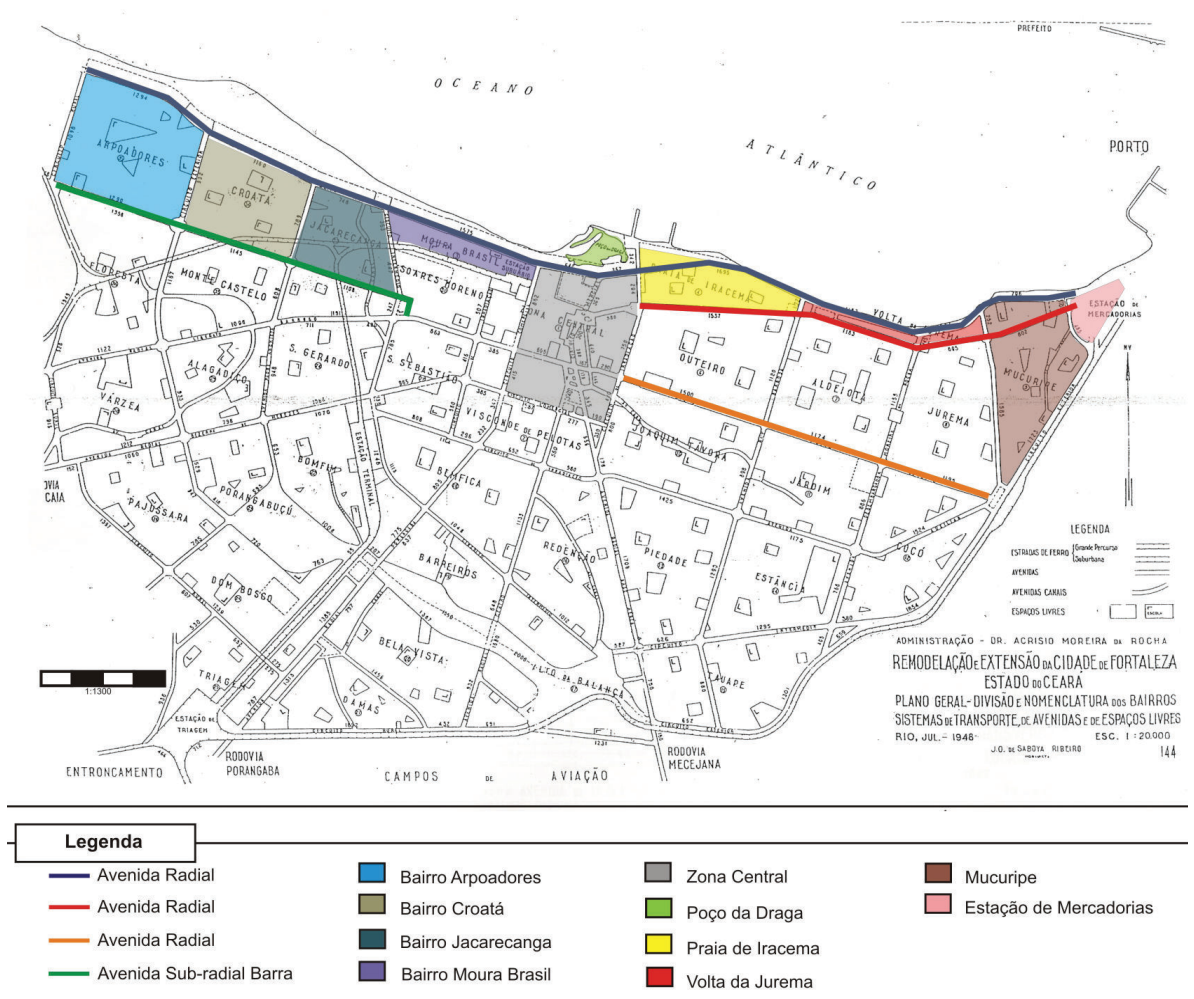

Figura 3 - Esquematização sobre o "Plano Diretor de Remodelação e Extensão da Cidade de Fortaleza", realizado por Saboya Ribeiro em 1947, ressaltando o projeto de elaboração de novos bairros e vias de circulação na zona costeira de Fortaleza.

Fonte: Adaptado de Ribeiro (1947). 
Logo após, próximo às construções do novo porto e às dunas do Mucuripe, aparecem alguns núcleos de ocupação urbana espontânea, habitados por pescadores e operários do porto, esboçando os arruamentos primitivos da atual Varjota. A partir daí, estende-se apenas a grande área, então, deserta de dunas correspondente aos atuais bairros Papicu e Praia do Futuro (CORTEZ, 2000, p. 270).

Percebemos na planta de Ribeiro a quase total ausência de arruamento ligando àquela região da Barra do Ceará ao restante da Cidade. A esse desinteresse residia o não intento de oferecer acessibilidade, ao restante da cidade, àqueles que ali residiam, além da quase inexistência de atividades naquela zona à exceção das pontuais práticas dos banhos de mar, marcando presença apenas a pesca e o desembarque de hidroaviões da Condor, com uma freqüência que era diminuta (CONDOR, 1933).

A carência de vias de acesso não era presente apenas àquela parte da Cidade. Não havia ligações entre o Barro Vermelho atual Antônio Bezerra, Otávio Bonfim e Mucuripe, por exemplo. Dessa forma, Saboya Ribeiro propõe um novo traçado, com a criação de vias radiais, perimetrais, transversais e diagonais, visando ampliar o perímetro urbano, dando maior acessibilidade aos diversos pontos de ocupação que emergiam na capital, desafogando o fluxo da zona central e traçando um novo direcionamento urbano para a cidade.

Saboya Ribeiro apresenta em seu projeto a proposta de criação da avenida do Mucuripe, avenida radial do Outeiro, avenida radial Beira-mar e avenida sub-radial da Barra do Ceará2. Dentre essas se destaca o projeto da avenida do Mucuripe, que partindo do objetivo que o urbanista teve em inserir a localidade do novo porto em seu Plano, essa nova via surgia com vistas a atender a necessidade de ligação rodoviária entre a zona portuária emergente e a zona comercial da cidade, indo da Praça do Ferreira ao Porto do Mucuripe.

Tendo em vista as limitações administrativas, diante dos graves problemas enfrentados com a urbanização, e tentando preservar as belezas naturais da região, o projeto de Saboya Ribeiro propõe também áreas livres de uso público3, como o do Parque da Barra do Ceará4 e Parque Beira-mar5.

Analisando o projeto de Saboya Ribeiro percebemos a preocupação do urbanista em dotar o litoral da cidade de melhores condições urbanísticas. Nota-se que há o particular interesse de inserir no projeto urbano o Arraial Moura Brasil6 (Figura 4). Propondo a construção de habitações populares, Saboya Ribeiro propunha um aproveitamento racional do setor, "destacando como principal motivo sua proximidade com o centro comercial e a zona fabril, locais de absorção de grande mão de obra ali residente" (SALES, 1996, p. 40), estabelecendo a criação do bairro Moura Brasil, destinado para os trabalhadores que prestavam serviço na zona comercial da cidade.

O urbanista defendia a preservação da paisagem natural e sua integração na composição urbana da cidade. Além de estabelecer diretrizes para o aproveitamento do vale do Pajeú e das zonas lacustres da Cidade, o urbanista tinha também planos para o litoral. Para tanto, existe lei anexa ao projeto de Ribeiro que define:

Art. $56^{\circ}$ - Toda a orla litorânea, a exceção dos trechos ocupados pelos serviços portuários, ficará sujeita à Prefeitura, que impedirá qualquer utilização que concorra para o afeiamento (sic) ou conspurcação de suas praias, sem embargo das exigências que forem feitas pelo Governo da União e do Estado [...] (FORTALEZA, 1950, p. 443)

Ao propor a avenida radial Beira-mar, que ligando o bairro Arpoadores ao porto do Mucuripe percorria todo o litoral norte da cidade, Saboya Ribeiro estabelecia em seu projeto que toda a orla marítima da margem dessa via, à exceção das duas zonas portuárias, fosse preservada de qualquer utilização que "concorresse para seu enfeiamento [sic] ou conspurcação de suas praias" (SALES, 1996, p. 109).

Essa preocupação vinha inserida num período em que outras praias despontavam em Fortaleza. Narcélio Limaverde (1999, p. 71) afirma que o bairro do Arpoador (atual Pirambu), apesar de configurar-se àquela época como o novo ponto de escoamento dos dejetos da cidade, passava 
a atrair estudantes e pobres que disputavam com os urubus um lugar ao sol. A prática dos banhos de mar popularizavam-se para essa coletividade, inserindo naquele espaço pequenos bares, locais para mudança de roupa e aluguel de calção para banho.

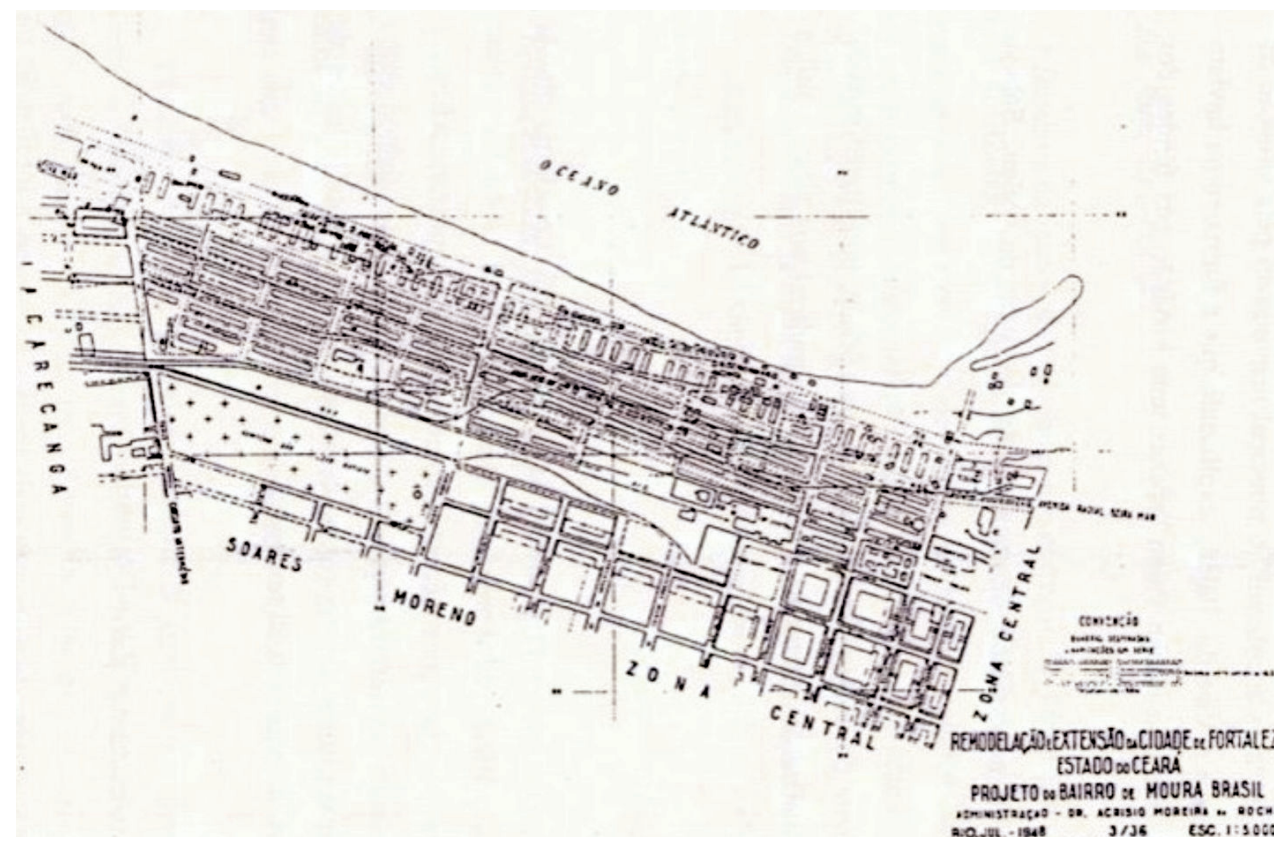

Figura 4 - Proposta para o Bairro Popular Moura Brasil, do Plano de Remodelação e Extensão de Saboya Ribeiro Fonte: Ribeiro (1947).

No entanto, novamente um projeto urbano pensado para Fortaleza foi impedido de ser realizado. Fernandes (2004) associa esse fator novamente à predominância das decisões particulares dos proprietários de imóveis ao impedirem a abertura de vias e o alargamento de ruas que gerassem perdas de lotes. O poder público não conseguia estabelecer autoridade frente aos interesses imobiliários de uma elite que ali se manifestava.

Dessa forma, a Cidade permanecia sem um planejamento com vias de concretização há setenta e dois anos, desde a planta de Adolfo Herbster de 1875. Na década de 1940 a cidade já inseria o seu perfil litorâneo até a ponta do Mucuripe, algo impensável para o período de Herbster e, portanto, sem qualquer planejamento concretizado.

A necessidade de planejamento para o litoral toma acuidade principalmente após a conclusão do porto do Mucuripe. Devido um conjunto de carências de planejamento à construção do porto do Mucuripe, ocorre uma ausência de sedimentação por todo o litoral norte da cidade. Dessa forma, o espaço litorâneo de Fortaleza toma ares de tragédia devido a destruição das construções próximas a praia, principalmente nas imediações da praia de Iracema.

Com a chegada da lua cheia, tem início o avanço assustador da maré sobre as praias de Fortaleza, criando um ambiente de preocupação entre os habitantes daquelas zonas. A lua cheia começou a 18 deste mês e desde então vem se observando a arremetida das águas contra as casas que ainda encontram-se de pé.

O avanço não tomou proporções gigantescas, pois o vento é brando, o que não se verificará em fevereiro, quando voltará a se acentuar as fúrias das marés. (ESTÃO..., 1946, p. 9)

Percebemos nas leituras jornalísticas da época que ainda não havia associação direta do ocorrente no litoral da cidade com a falta de planejamento, mas como sendo de causa natural decorrente da ressaca do mar. Notadamente, o perfil cartográfico de Fortaleza planejado por Saboya Ribeiro, toma um novo direcionamento, com o mar avançando mais de 300 metros em direção ao continente. 
Ao analisar os projetos cartográficos fortalezenses das décadas de 1930-140 é possível perceber a complexidade perpassada na cidade em função da expansão urbana e sua ocupação litorânea. Saboya Ribeiro traz em seu plano a proposta de inserção do litoral na dinâmica de expansão da cidade. Com cintas de ruas e avenidas ligando a praia ao restante de Fortaleza, o Plano de Remodelação e Extensão de Ribeiro além de promover um novo perfil urbano, propôs a inserção da capital cearense no contexto que Sales (1996, p. 99) define como "moderna cultura urbana brasileira".

Apesar da não aplicação do plano de Saboya Ribeiro, tal proposição influenciou no redirecionamento do espaço urbano da cidade. As imagens tratadas no Plano Diretor surgem como signos de uma época, contendo um discurso articulado com os processos políticos, econômicos e culturais da sociedade que as elaboraram. Além de representar a cidade, a cartografia também é uma forma de agir no urbano, onde através dos discursos inseridos na elaboração de tais documentos, o homem (re)apresenta a ordem social vivida, refletindo também as contradições entre os agentes de planejamento e produção do espaço da cidade.

Portanto, perceber a cidade é mais do que apenas ver as imagens cartográficas que rodeiam o cotidiano, mas tê-las como informações para o seu planejamento, buscando adquirir novas formas para perceber o espaço. Além de servir como marca de uma materialidade passada, a reprodução cartográfica de Saboya Ribeiro para Fortaleza concretiza a representação do modo de vida social, os valores culturais, individuais e coletivos perpassados na cidade.

\section{REFERÊNCIA BIBLIOGRÁFICA}

AVISO. Correio do Ceará, Fortaleza, 04 mar. 1921. p. 7.

BAKER, Geoffrey H.; Le Corbusier: uma análise da forma; São Paulo: Martins Fontes, 2006.

BORGES, Marília Santana. Quarteirão sucesso da Cidade: o art d'eco e as transformações arquitetônicas na Fortaleza de 1930 e 1940. 2006. Dissertação (Mestrado em Arquitetura e Urbanismo) - Universidade de São Paulo, São Paulo, 2006.

BRASIL. Ministério dos negócios da agricultura comercio e obras publicas. À directoria Central. Rio de Janeiro [s. n.], 1862.

CONDOR. Correio do Ceará, Fortaleza, 13 jun. 1933.

CORTEZ, Amanurício Pereira. O Estado e a formação da paisagem urbana de Fortaleza quanto à vegetação arbórea: enfoques urbanístico e de sustentabilidade. Dissertação (Mestrado em Desenvolvimento e Meio Ambiente) - Universidade Federal do Ceará, Fortaleza, 2000.

COSTA, Maria Clélia Lustosa. Fortaleza: expansão urbana e organização do espaço. In: SILVA, José Borzacchiello da; DANTAS, Eustógio Wanderley Correia; CAVALCANTE, Tércia. Ceará: um novo olhar geográfico. Fortaleza: Edições Demócrito Rocha, 2005.

DANTAS, Eustógio Wanderley Correia. Da capital do sertão à cidade do sol: Fortaleza e o processo de litoralização do Ceará. Caderno de Geografia: notas sobre o urbano cearense do litoral ao sertão. Fortaleza, Ceará, v. 1. p. 42-71, 1998.

ESTÃO novamente em perigo as casas da praia de Iracema. O Povo, Fortaleza, 24 jan. 1946, p. 9.

FERNANDES, F. R. C. As transformações espaciais e ambientais na área central de Fortaleza: uma análise das suas perspectivas de renovação urbana. 2004. Dissertação (Mestrado em Desenvolvimento e Meio Ambiente) - Universidade Federal do Ceará, Fortaleza, 2004.

FIGUEIREDO, Nestor de. Projeto de remodelação e extensão de Fortaleza. Fortaleza [s.n.], 1933.

FINALMENTE a inauguração do novo porto. Correio do Ceará, Fortaleza, 25 jan. 1928.

FORTALEZA, Prefeitura Municipal. Lei no 188, de 16 de maio de 1950. Diário oficial do Município, 1950.

FREITAS, Mirtes. A cidade dos clubes: modernidade e glamour na Fortaleza de 1950-1970. Fortaleza: Expressão Gráfica Editora, 2005.

GIRÃO, Raimundo. Geografia estética de Fortaleza. Fortaleza: Edições UFC, 1997. 
INGLOURIOUS Basterds. Direção: Quentin Tarantino. Produção: Lawrence Bender. Intérpretes: Brad Pitt, Melanie Laurent, Christoph Waltz, Eli Roth e outros. Roteiro: Quentin Tarantino. Música: Enio Morricone. [S. 1.] The Weinstein Company / Universal Pictures, 2009. 1 Blu-ray (153 min.).

KNAUSS, Paulo . Imagem do espaço, imagem da história: a representação espacial da cidade do Rio de Janeiro. Tempo, Rio de Janeiro, v. 2, n. 3, p. 135-148, 1997.

LACOSTE, Yves. An illustration of geographical warface. Antipode, no 5, p. 1-13, 1973.

LÉVY, Jacques. Uma virada cartográfica. In: ACSELRAD, Henri (org.). Cartografias sociais e Território. Rio de Janeiro: IPPUR/UFRJ, 2008.

LIMAVERDE, Narcélio. Fortaleza, histórias e estórias: memórias de uma cidade. Fortaleza: ABC Fortaleza, 1999.

RIBEIRO, José Otacílio de Saboya. Memorial justificativo do Plano de Remodelação e Extensão da Cidade de Fortaleza (apresentado à Prefeitura Municipal de Fortaleza em 1947). Revista do Instituto do Ceará. Fortaleza, Ceará, v. 69, p. 75-81, 1955.

RIBEIRO, José Otacílio de Saboya. Plano de Remodelação e Extensão da Cidade de Fortaleza. Fortaleza, [s.n.], 1947

RODRIGUES, Maria do Socorro Costa; SOUSA FILHO, Luciano Moreira de. Pecém: uma trajetória portuária. Fortaleza: SEBRAE/CE, 2007.

SALES, José Albio Moreira de. O desenho da cidade moderna em Fortaleza: um estudo dos planos de Saboya Ribeiro e Hélio Modesto. 1996. Dissertação (Mestrado em Desenvolvimento Urbano) - Universidade Federal de Pernambuco, Recife 1996.

SOUSA, Neimar Machado de. Cartografia histórica. Tellus. [s.1.] v. 2, p. 173-175, 2002.

SOUZA, Maria Salete. O crescimento das cidades no Ceará e sua evolução. In: SIMPÓSIO NACIONAL

DE GEOGRAFIA URBANA, 4., 1995, Fortaleza. Anais do IV Simpósio Nacional de Geografia Urbana. Fortaleza: NUTEC, 1995, p. 105-111.

TUCCI, Uglo. Atlas. In: LE GOFF, J. et al. Memória histórica. Lisboa: Imprensa Nacional/Casa da Moeda, 1984.

VIAGENS com a agência Lloyd Brasileiro. Correio do Ceará, Fortaleza, 13 jan. 1929. p. 6.

Trabalho enviado em fevereiro de 2012

Trabalho aceito em março de 2012 